\title{
Three new Cryptochetum Rondani, 1875 (Diptera: Cryptochetidae) from Yunnan Province, China and an identification key to Chinese species
}

\author{
Yuqiang $\mathrm{XI}^{1} \&$ Xinming $\mathrm{YIN}^{2, *}$ \\ ${ }^{1,2}$ Department of Entomology, College of Plant Protection, \\ Henan Agricultural University, Zhengzhou, China. \\ *Corresponding author: xinmingyin@126.com \\ 1Email: yuqiangxi2012@126.com \\ ${ }^{1}$ urn:1sid:zoobank.org:author:4E322DCB-E034-4B7C-9132-93D768A947E0 \\ ${ }^{2}$ urn:1sid:zoobank.org:author:F898F149-CF6B-4EF1-808A-6B01D90A64D9
}

\begin{abstract}
Three species of the genus Cryptochetum Rondani, 1875 from China are described and figured as new to science: C. euthyiproboscise sp. nov., C. glochidiatusum sp. nov., and C. longilingum sp. nov. An identification key to the known species of Cryptochetum from China is presented. The type specimens of the new species are deposited in the Henan Agricultural University.
\end{abstract}

Keywords. Cryptochetum, Diptera, new species, China.

Xi Y. \& Yin X. 2020. Three new Cryptochetum Rondani, 1875 (Diptera: Cryptochetidae) from Yunnan Province, China and an identification key to Chinese species. European Journal of Taxonomy 605: 1-15.

https://doi.org/10.5852/ejt.2020.605

\section{Introduction}

Cryptochetum Rondani, 1875 is a genus of small (body length: 1.0-3.0 mm) cryptochetid flies. The genus is recognized by the following characteristics: body stubby and compact, shiny and brownish black with a metallic blue-green luster; eye very large, ocelli present; ocellar triangle shiny black with metallic luster; frons without setae, orbital setae lacking; postpedicel large, with complete absence of an antennal arista; scutellum large, approximately triangular; wing hyaline with greenish and purplish reflections; veins brown, costal vein (C) extending to end of $R_{4+5}$ or $M_{1}$ (Yang \& Yang 1996). The Chinese species were reviewed and 15 species are now recognized (Xi \& Yang 2015; Yang \& Yang 1996, 1998a, 1998b, 2001). Larvae of most Cryptochetum are endoparasitic of various scale insects of the family Monophlebidae (Coccoidea) (Thorpe 1941a, 1941b; Foote \& Arnaud 1958; Yang \& Yang 1996).

Yunan Province $\left(21^{\circ} 08^{\prime}-29^{\circ} 15^{\prime} \mathrm{N}, 97^{\circ} 31^{\prime}-106^{\circ} 11^{\prime} \mathrm{E}\right)$ is located in the south-west part of China with various climates and is rich in wildlife resources. In this paper, three species of the genus Cryptochetum 
from China are described as new to science. An identification key to the known species of Cryptochetum occurring in China is presented.

\section{Material and methods}

Terminalia preparations were made by removing and macerating the apical portion of the abdomen in glacial acetic acid, then rinsed in distilled water before being stored in glycerine-filled microvials. After examination, they were transferred to fresh glycerine and stored in a microvial on the pin below the specimen or moved to an ethanol tube together with the wet specimens. Specimens examined are deposited in the Entomological Museum of Henan Agricultural University (EMHAU), Zhengzhou. The general terminology follows Cumming \& Wood (2017).

\section{Abbreviations for morphological terms}

$\begin{array}{ll}\mathrm{C} & =\text { costal vein } \\ \text { cerc } & =\text { cercus } \\ \mathrm{dm}-\mathrm{m} & =\text { discal medical crossvein } \\ \text { epand } & =\text { epandrium } \\ \text { gon } & =\text { gonopods } \\ \text { hypd } & =\text { hypandrium } \\ \mathrm{M}_{1} & =\text { first branch of media } \\ \mathrm{M}_{4} & =\text { fourth branch of media } \\ \mathrm{ph} & =\text { phallus } \\ \mathrm{R}_{1} & =\text { anterior branch of radius } \\ \mathrm{R}_{2+3} & =\text { second branch of radius } \\ \mathrm{R}_{4+5} & =\text { third branch of radius } \\ \mathrm{S}_{\mathrm{c}} & =\text { subcostal vein } \\ \text { sur } & =\text { surstylus }\end{array}$

\section{Results}

The genus Cryptochetum is now represented by 18 species from China and an identification key to species is provided below.

\section{Key to species of Cryptochetum Rondani, 1875}

1. Ocellar triangle small, separated from antennal base; costal vein (C) extending to vein $M_{1}$ 2

- Ocellar triangle large, reaching antennal base; costal vein (C) extending to vein $\mathrm{R}_{4+5}$ or slightly beyond apex of wing

2. Wing crossvein dm-m curved inward (Fig. 22)

3. Wing vein $\mathrm{R}_{4+5}$ terminating at apex of wing

- Wing vein $\mathrm{R}_{4+5}$ terminating before apex of wing, located between $\mathrm{R}_{4+5}$ and $\mathrm{M}_{1}$

4. Wing vein $\mathrm{M}_{1}$ between $\mathrm{r}-\mathrm{m}$ and $\mathrm{dm}-\mathrm{m}$ crossveins as long as $\mathrm{dm}-\mathrm{m}$ crossvein (Fig. 24) C. tianmuense Yang \& Yang, 2001

- Wing vein $\mathrm{M}_{1}$ between $\mathrm{r}-\mathrm{m}$ and $\mathrm{dm}-\mathrm{m}$ crossveins longer than $\mathrm{dm}-\mathrm{m}$ crossvein

5. Wing vein $\mathrm{M}_{1}$ between $\mathrm{r}-\mathrm{m}$ and $\mathrm{dm}-\mathrm{m}$ crossveins $2.0 \times$ as long as $\mathrm{dm}-\mathrm{m}$ crossvein (Fig. 25) C. acutulum Yang \& Yang, 1996

- Wing vein $\mathrm{M}_{1}$ between $\mathrm{r}-\mathrm{m}$ and $\mathrm{dm}-\mathrm{m}$ crossveins $<2.0 \times$ as long as $\mathrm{dm}-\mathrm{m}$ crossvein 6 
6. Wing vein $\mathrm{M}_{1}$ between $\mathrm{r}-\mathrm{m}$ and $\mathrm{dm}-\mathrm{m}$ crossveins $1.2 \times$ as long as $\mathrm{dm}-\mathrm{m}$ crossvein (Fig. 9)

- Wing vein $\mathrm{M}_{1}$ between $\mathrm{r}-\mathrm{m}$ and $\mathrm{dm}-\mathrm{m}$ crossveins $1.5 \times$ as long as $\mathrm{dm}-\mathrm{m}$ crossvein

7. Antennal postpedicel slightly acute apically (Fig. 26)

C. zalatilabium Xi \& Yang, 2015

- Antennal postpedicel slightly blunt apically

8. Knob of haltere dark brown; distal portion of $\mathrm{M}_{4}$ (part beyond crossvein $\mathrm{dm}-\mathrm{m}$ ) $2.0 \times$ as long as dm-m crossvein (Fig. 3)

C. euthyiproboscise sp. nov.

- Knob of haltere dark yellow; distal portion of wing vein $\mathrm{M}_{4}$ (part beyond crossvein $\left.\mathrm{dm}-\mathrm{m}\right) 1.5 \times$ as long as dm-m crossvein (Fig. 17)

C. longilingum sp. nov.

9. Costal wing vein (C) extending beyond end of vein $\mathrm{R}_{4+5}$; vein $\mathrm{M}_{1}$ between $\mathrm{r}-\mathrm{m}$ and $\mathrm{dm}-\mathrm{m}$ crossveins virtually as long as dm-m crossvein (Fig. 27)

C. kunmingense Yang \& Yang, 1996

- Costal wing vein $(C)$ extending to end of vein $R_{4+5}$; vein $M_{1}$ between $r-m$ and $d m-m$ crossveins shorter than dm-m crossvein

10. Apex of wing situated medially between veins $R_{4+5}$ and $M_{1}$

- Apex of wing closer to vein $R_{4+5}$ than to vein $M_{1}$

11. Wing vein $M_{1}$ between $r-m$ and $d m-m$ crossvein as long as vein $M_{4}$ (part beyond $d m-m$ crossvein) (Fig. 28)

C. fanjingshanum Yang \& Yang, 1988

- Wing vein $M_{1}$ between $r-m$ and $d m-m$ crossvein shorter than vein $M_{4}$ (part beyond $d m-m$ crossvein)

12. Distal portion of wing vein $\mathrm{M}_{4}$ (part beyond dm-m crossvein) $1.7 \times$ as long as $\mathrm{dm}-\mathrm{m}$ crossvein; dm-m crossvein virtually straight (Fig. 29)

C. maolanum Yang \& Yang, 1996

- Distal portion of wing vein $\mathrm{M}_{4}$ (part beyond dm-m crossvein) $3.0 \times$ as long as dm-m crossvein; dm-m crossvein slightly curved (Fig. 30)

C. shaanxiense Xi \& Yang, 2015

13. Mid section of dm-m crossvein appreciably curved 14

- Mid section of $\mathrm{dm}$ - $\mathrm{m}$ crossvein perpendicular 15

14. Antennal postpedicel wide and flat, margin inclined apically (Fig. 31)

.C. yunnanum Xi \& Yang, 2015

- Antennal postpedicel slightly narrow and short, margin blunt and rounded apically (Fig. 32)

C. nonagintaseptem Yang \& Yang, 1998

15. Ocellar triangle approximately in equilateral triangle 16

- Ocellar triangle approximately in obtuse triangle

16. Apex angle of ocellar triangle slightly wider than distance between antennae; body slightly smaller (body length $1.5 \mathrm{~mm}$ ) (Fig. 33)

C. medianum Yang \& Yang, 1998

- Apex angle of ocellar triangle slightly narrower than distance between antennae; body slightly larger (body length $3.5 \mathrm{~mm}$ ) (Fig. 34)

C. sinicum Yang \& Yang, 1996

17. Apical angle of ocellar triangle slightly wider than distance between antennae; antennal postpedicel acute apically (Fig. 35) C. acuticornutum Yang \& Yang, 1998

- Apical angle of ocellar triangle nearly equal to distance between antennae; antennal postpedicel with apical margin inclined inward (Fig. 36)

C. beijingense Yang \& Yang, 1996 


\section{Descriptions of new species}

Class Diptera Linnaeus, 1758

Family Chryptochetidae Brues \& Melander, 1932

Genus Cryptochetum Rondani, 1875

Cryptochetum euthyiproboscise sp. nov. urn:1sid:zoobank.org:act:0DD2BF7C-1EC1-48FD-AF31-5D3883B239CE

Figs $1-7$

\section{Diagnosis}

Ocellar triangle approximately in isosceles triangle, apical angle shorter than the distance between antennae. Surstylus slightly narrowed and sharp apically.

\section{Etymology}

The species epithet refers to the straight palpus.

\section{Type material}

\section{Holotype}

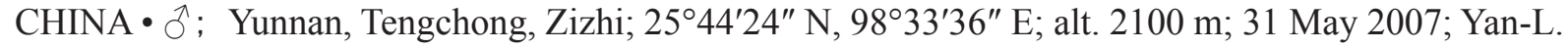
Li leg.; EMHAU CR101.

\section{Paratypes}

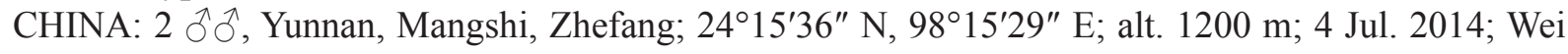
Zhang leg.; EMHAU DICR0013.
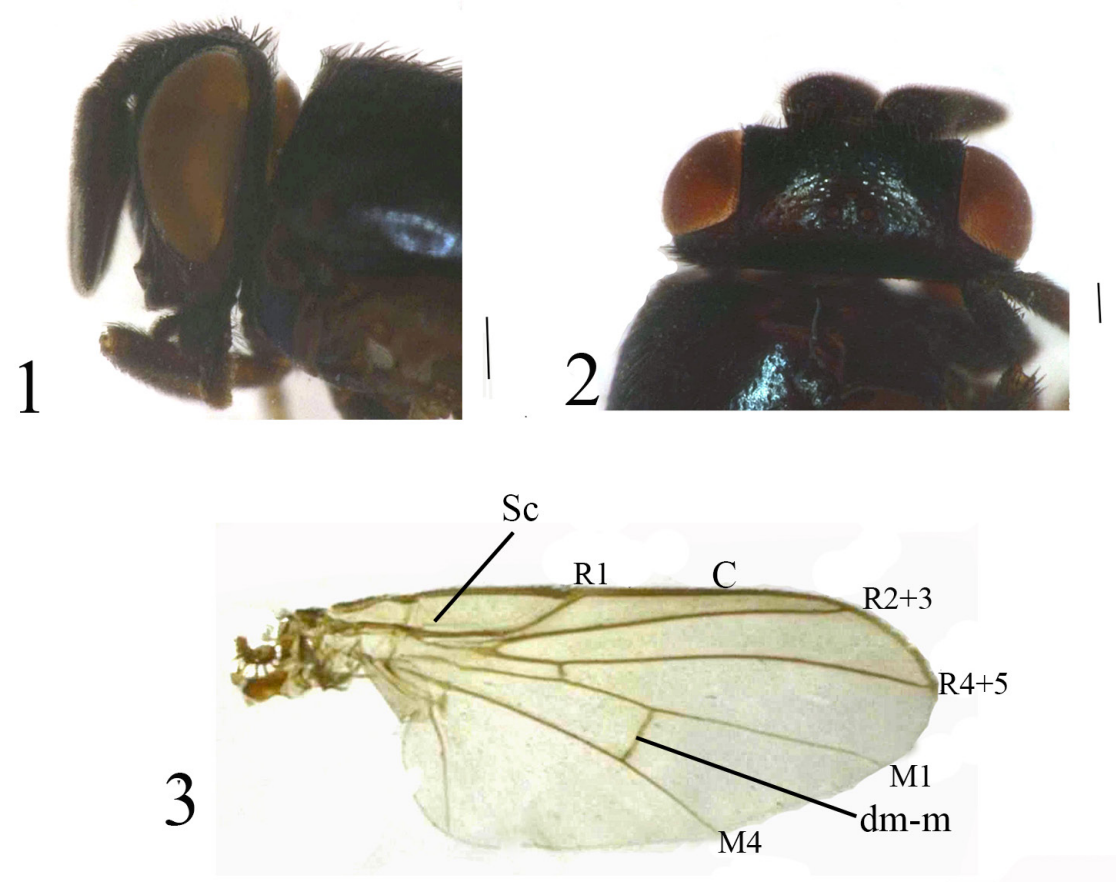

Figs 1-3. Cryptochetum euthyiproboscise sp. nov., holotype, ô (CR101). 1. Head, lateral view. 2. Head, dorsal view. 3. Wing, dorsal view. Scale bar $=0.1 \mathrm{~mm}$. 


\section{Description}

MALE. Body length: 2.2-2.4 mm; wing length: 2.6-2.8 mm.

HeAD. Darkish brown (Fig. 1); ocellar triangle shiny brown with metallic luster (Fig. 2), approximately in isosceles triangle, apex slightly flat; lunule strap-shaped, very narrow, brown. Eye red, bare, $1.8 \times$ as high as long, gena approximately $1 / 8$ of eye height. Setae and setulae on head black; ocelli darkish yellow, placed close together. Ocellar triangle with short setulae, punctures at bases of setulae conspicuous; frons without setae, orbital setae lacking; postvertical setae erect, considerably stouter and longer than other setulae on vertex. Antenna brown with microtomentum, large, same length as face; scape and pedicel with black setulae at middle and margin; postpedicel with pubescence, irregularly rectangular, front margin straight, apical margin curved, $0.5 \mathrm{~mm}$ long, $0.2 \mathrm{~mm}$ wide, apical angle with stout conical tubercle, a little longer than surrounding setulae. Proboscis flat and straight, brown, with short sparse

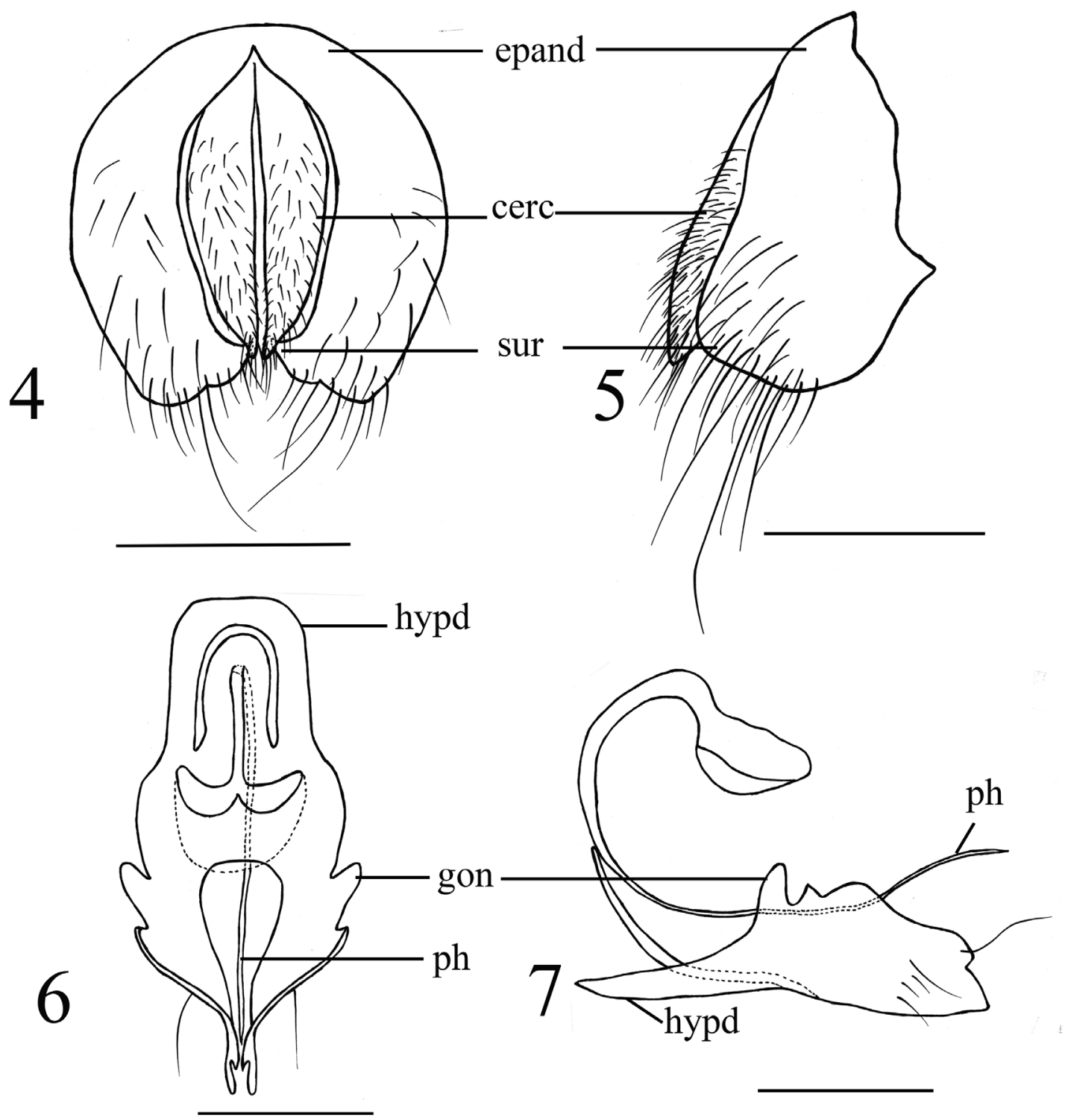

Figs 4-7. Cryptochetum euthyiproboscise sp. nov., holotype, ô (CR101). 4. Dorsal view. 5. Lateral view. 6. Dorsal view. 7. Lateral view. Scale bars: $4-5=0.1 \mathrm{~mm}$; $6-7=0.05 \mathrm{~mm}$. 
black setulae, labellum slightly wide. Palpus short, ca $0.2 \mathrm{~mm}$ long, apically rounded, darkish brown with short dense black pubescence, margin with short sparse setulae.

Thorax. Shiny, darkish brown with brownish stripes and metallic blue-green luster; scutellum shiny, blackish brown. Setae and setulae on thorax black, punctures at bases of setulae deep and numerous; scutellum large, approximately triangular, wide and rounded apically, $0.5 \times$ as long as thorax. Apical setae longer and stouter than other setae. Anepisternum brown with setulae, katepisterunum and anepimeron brownish, bare. Legs slender, blackish brown except tarsi yellowish. Setae and setulae on legs black. Wing hyaline with greenish and purplish reflections, unspotted, $2.3 \times$ as long as wide; veins brown; costal vein (C) extending to end of $\mathrm{R}_{4+5}$ and terminating at apex of wing; subcostal vein (Sc) weak, slightly angulated; $R_{1}$ curved, not angulated, $R_{2+3}$ and $R_{4+5}$ parallel for $4 / 5$ along their lengths, then diverging to wing margin; $\mathrm{r}-\mathrm{m}$ short; $\mathrm{M}_{1}$ between $\mathrm{r}-\mathrm{m}$ and $\mathrm{dm}-\mathrm{m} 1.5 \times$ as long as $\mathrm{dm}-\mathrm{m}, \mathrm{dm}-\mathrm{m}$ slightly sinuous, forming an angle nearly at $90^{\circ}$ with $\mathrm{M}_{4}$, distal portion of $\mathrm{M}_{4}$ (the part beyond dm-m) $1.9 \times$ as long as dm-m (Fig. 3). Calypter brownish, with brownish microtrichae, margin with brownish setulae. Knob of haltere dark brown, stalk brown.

AвDOMEN. Brownish black with a metallic blue-green luster, wide and slightly flattened. Setae and setulae on abdomen black. Male terminalia: epandrium (Figs 4-5) reduced to thick band dorsally, with sides broadest in middle, with setulae; surstylus slightly narrowed and sharp apically; cercus rather large, with dense setulae. Hypandrium (Figs 6-7) n-shaped; gonopods small and symmetric; phallus slender, distipallus slightly wide.

\section{Female}

Unknown.

\section{Distribution}

China (Yunnan).

\section{Remarks}

This new species is somewhat similar to C. kunmingense Yang \& Yang, 1996, but may be separated from it by $\mathrm{M}_{1}$ between $\mathrm{r}-\mathrm{m}$ and $\mathrm{dm}-\mathrm{m} 1.6 \times$ as long as $\mathrm{dm}-\mathrm{m}$; distal potion of $\mathrm{M}_{4}$ (the part beyond $\mathrm{dm}-\mathrm{m}$ ) $1.9 \times$ as long as dm-m. In C. kunmingense, $\mathrm{M}_{1}$ between $\mathrm{r}-\mathrm{m}$ and $\mathrm{dm}-\mathrm{m} 1.2 \times$ as long as $\mathrm{dm}-\mathrm{m}$; distal potion of $\mathrm{M}_{4}$ (the part beyond dm-m) $1.4 \times$ as long as dm-m (Yang \& Yang 1996).

Cryptochetum glochidiatusum sp. nov.

urn:1sid:zoobank.org:act:AC6FB5F5-5312-4F14-BCD5-666297C62955

Figs $8-14$

\section{Diagnosis}

Ocellar triangle approximately in equilateral triangle, apical angle slightly wider than the distance between antennae. Surstylus extremely narrowed and blunt apically.

\section{Etymology}

The species epithet refers to the shape of epandrium, which is spheroid in dorsal view.

\section{Type material}

\section{Holotype}

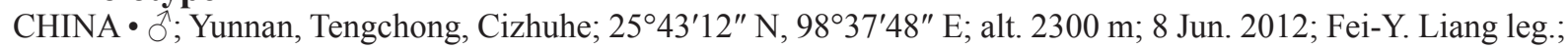
EMHAU CR122. 


\section{Paratypes}

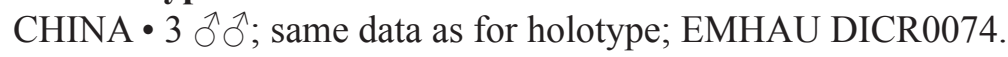

\section{Description}

MALE. Body length: 1.6-1.8 mm; wing length: $1.5-1.6 \mathrm{~mm}$.

HEAD. Black (Fig. 8); ocellar triangle shiny black with metallic luster (Fig. 9), approximately in equilateral triangle, apex slightly flat; lunule strap-shaped, very narrowed, sooty black. Eye darkish red, bare, $1.8 \times$ as high as long, gena approximately one fourteenth of eye height. Setae and setulae on head black; ocelli darkish yellow, placed close together. Ocellar triangle with short setulae, punctures at bases of setulae conspicuous; frons without setae, orbital setae lacking; postvertical setae erect, considerably stouter and longer than other setulae on vertex. Antenna darkish brown with microtomentum, large, shorter than face; scape and pedicel with black setulae at middle and margin; postpedicel with pubescence, irregularly rectangular, front margin straight, apical margin curved, $0.4 \mathrm{~mm}$ long, $0.2 \mathrm{~mm}$ wide, apical angle with stout conical tubercle, nearly as long as surrounding setulae. Proboscis flat and short, brownish yellow, with short sparse black setulae, labellum slightly wide. Palpus very short, apically enlarged and rounded, dark brown with short dense black pubescence, margin with short sparse setulae.

Thorax. Shiny, blackish brown with metallic blue-green luster; scutellum shiny, blackish brown. Setae and setulae on thorax black, punctures at bases of setulae deep and numerous; scutellum large, approximately triangular, wide and rounded apically, $0.5 \times$ as long as thorax. Apical setae longer and stouter than other setae. Anepisternum darkish brown with setulae, katepisterunum and anepimeron brown, bare. Legs slender, blackish brown except tarsi darkish yellow. Setae and setulae on legs black. Wing hyaline with greenish and purplish reflections, unspotted, slightly $1.8 \times$ as long as wide; veins brown; costa vein (C) extending to end of $\mathrm{R}_{4+5}$ and terminating before apex of wing; subcostal vein (Sc) weak, not angulate; $\mathrm{R}_{1}$ curved, not angulate, $\mathrm{R}_{2+3}$ and $\mathrm{R}_{4+5}$ parallel for $4 / 5$ along their lengths, then
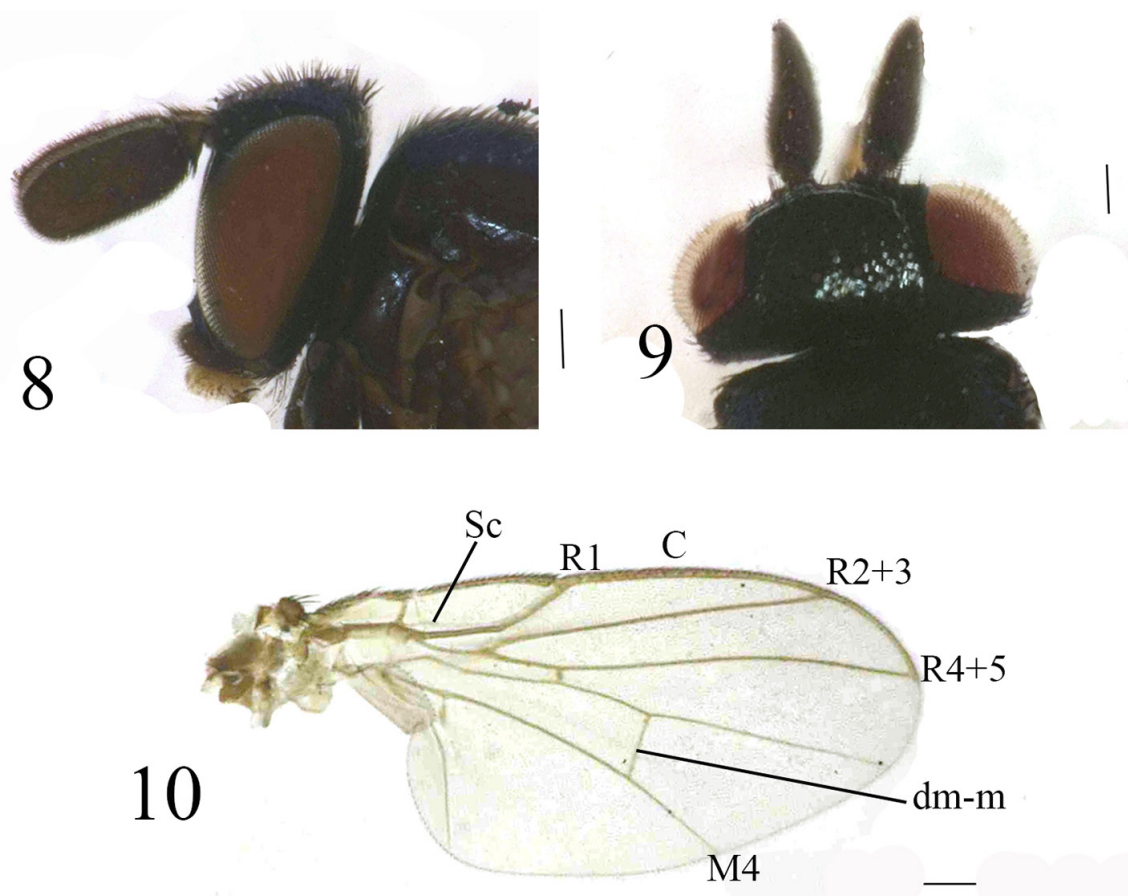

Figs 8-10. Cryptochetum glochidiatusum sp. nov., holotype, ổ (CR122). 8. Head, lateral view. 9. Head, dorsal view. 10. Wing, dorsal view. Scale bar $=0.1 \mathrm{~mm}$. 
diverging to wing margin; r-m short; $\mathrm{M}_{1}$ between $\mathrm{r}-\mathrm{m}$ and $\mathrm{dm}-\mathrm{m} 1.2 \times$ as long as $\mathrm{dm}-\mathrm{m}$, $\mathrm{dm}-\mathrm{m}$ slightly straight, not sinuous, forming an angle at $90^{\circ}$ with $\mathrm{M}_{4}$, distal portion of $\mathrm{M}_{4}$ ( the part beyond $\mathrm{dm}-\mathrm{m}$ ) $1.8 \times$ as long as dm-m (Fig. 10). Calypter brownish, with brownish microtrichae, margin with brownish setulae. Knob of haltere blackish brown, stalk brownish.

Aвdomen. Brownish black with a metallic blue-green luster, wide and slightly flattened. Setae and setulae on abdomen black. Male terminalia: epandrium (Figs 11-12) slightly wide and spheroid dorsally, with setulae apically; surstylus slightly blunt apically; cercus rather narrowed, with dense setulae. Hypandrium (Figs 13-14) irregularly rectangular; gonopods slightly small and symmetric; phallus thin, distipallus slightly enlarge.
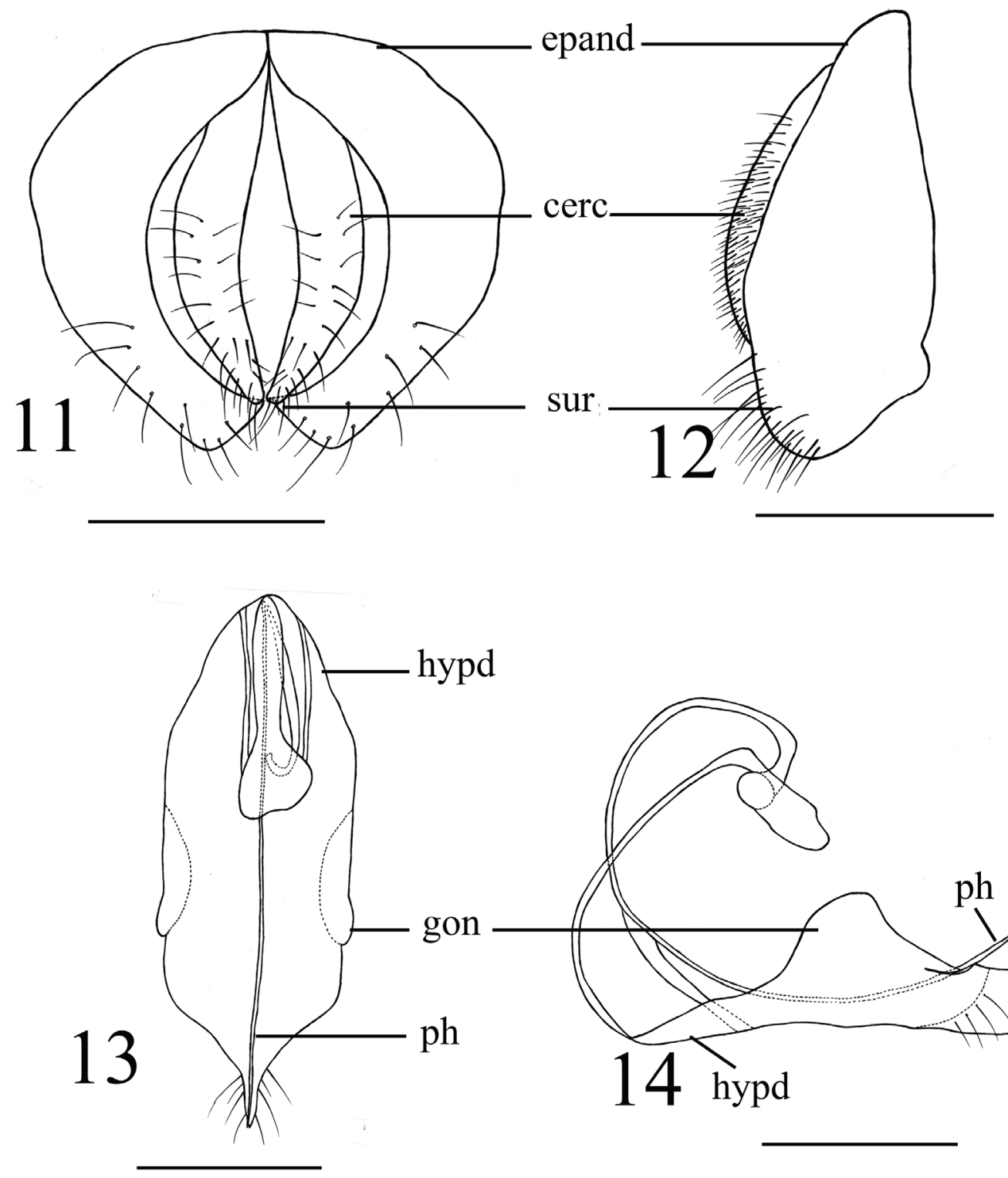

hypd

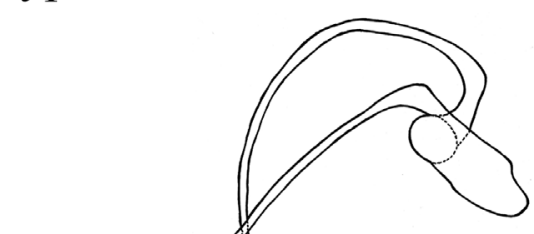

gon

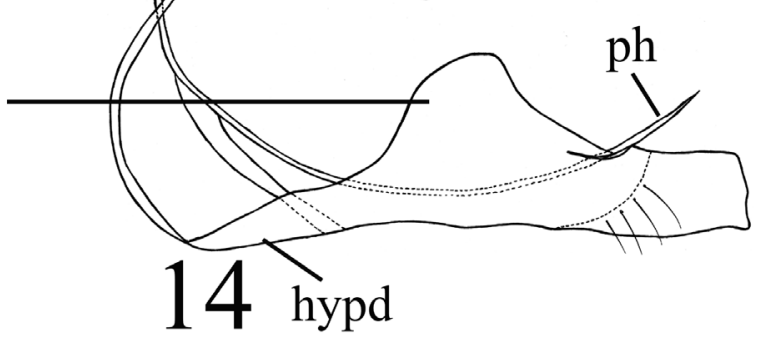

Figs 11-14. Cryptochetum glochidiatusum sp. nov., holotype, ô (CR122). 11. Dorsal view. 12. Lateral view. 13. Dorsal view. 14. Lateral view. Scale bars: $11-12=0.1 \mathrm{~mm} ; 13-14=0.05 \mathrm{~mm}$. 


\section{Female}

Unknown.

\section{Distribution}

China (Yunnan).

\section{Remarks}

This new species differs from other species of Cryptochetum as follows: the antenna is far away from the ocellar triangle, the postpedicel is irregularly rectangular; the epandrium is nearly circular and the cercus is rather narrowed.

\section{Cryptochetum longilingum sp. nov.}

urn:lsid:zoobank.org:act:F512F49C-833B-4D78-9EA0-05C0C8B831B0

Figs 15-21

\section{Diagnosis}

Ocellar triangle approximately in isosceles triangle, apical angle shorter than the distance between antennae. Surstylus slightly narrowed and blunt apically.

\section{Etymology}

The species epithet refers to the long proboscis.

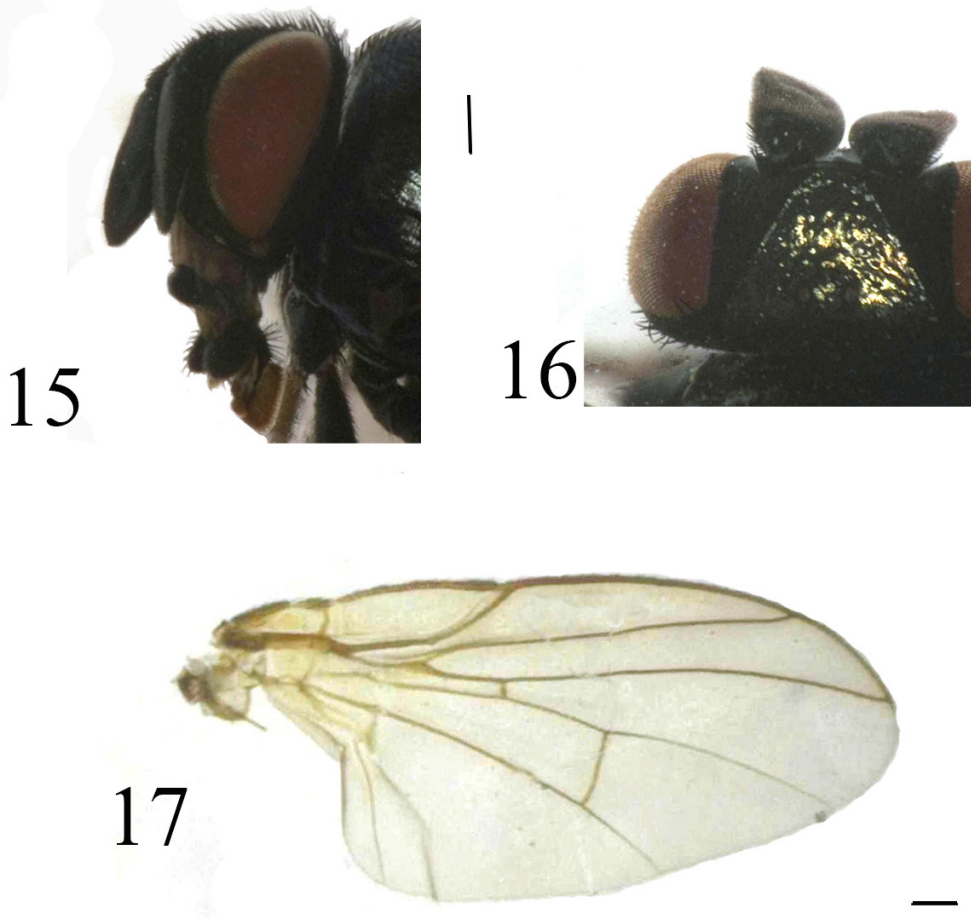

Figs 15-17. Cryptochetum longilingum sp. nov., holotype (CR154), ふ̊. 15. Head, lateral view. 16. Head, dorsal view. 17. Wing, dorsal view. Scale bar $=0.1 \mathrm{~mm}$. 


\section{Type material}

\section{Holotype}

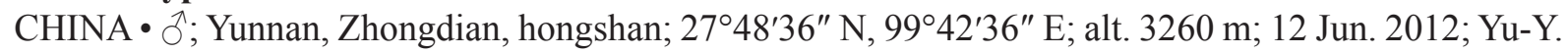
Wang leg.; EMHAU CR154.

\section{Paratypes}

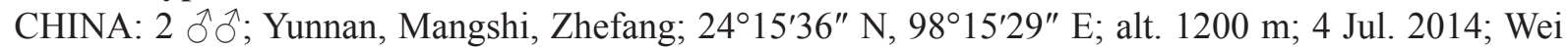
Zhang leg.; EMHAU DICR0096.

\section{Description}

MALE. Body length: 2.4-2.5 mm; wing length: 2.6-2.7 mm.
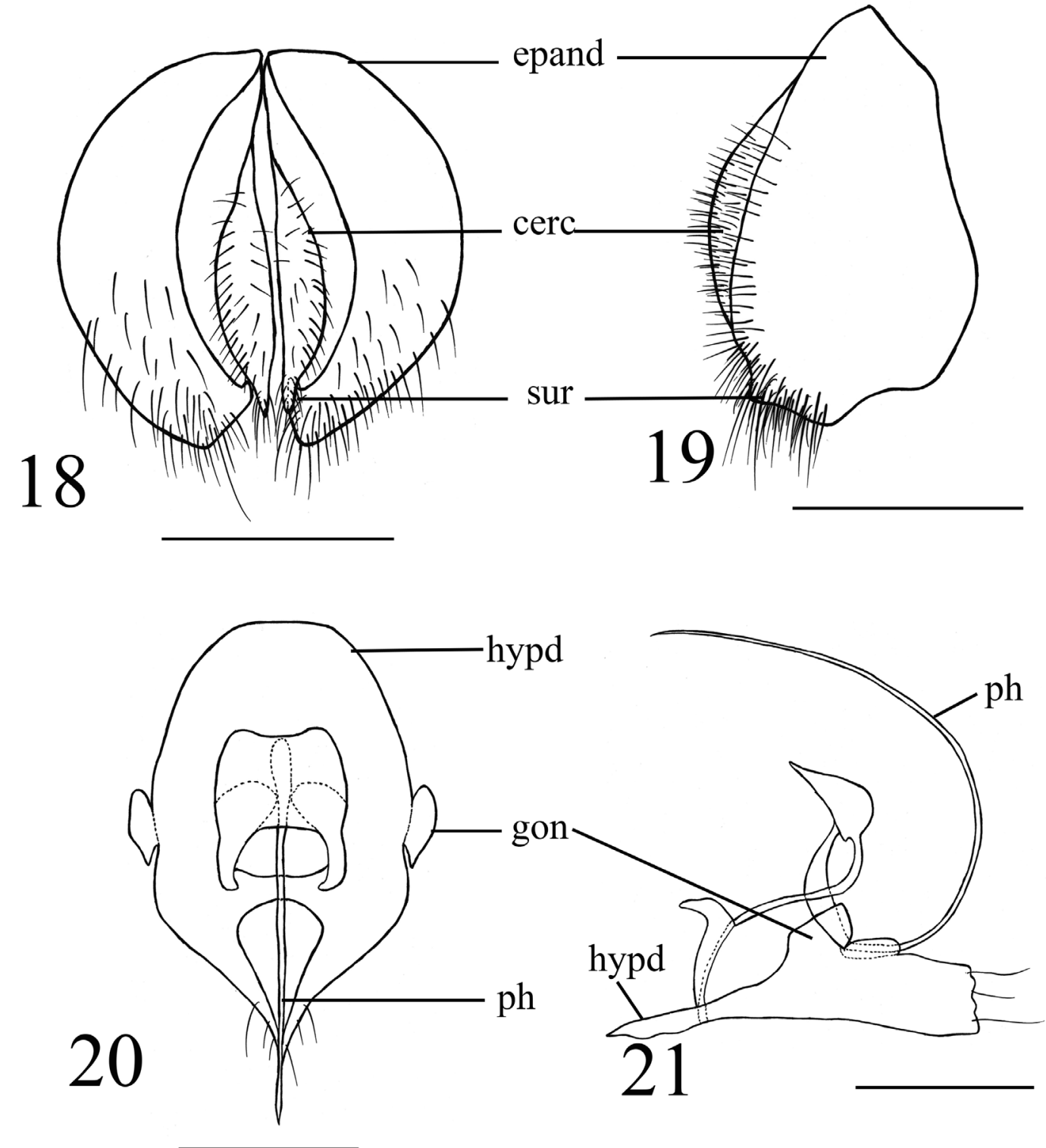

Figs 18-21. Cryptochetum longilingum sp. nov., holotype, $\widehat{\partial}$ (CR154). 18. Dorsal view. 19. Lateral view. 20. Dorsal view. 21. Lateral view. Scale bars: $18-19=0.1 \mathrm{~mm} ; 20-21=0.05 \mathrm{~mm}$. 
HEAD. Black (Fig. 15); ocellar triangle shiny black with metallic luster (Fig. 16), approximately in isosceles triangle, apex slightly flat; lunule strap-shaped, very narrow, sooty black. Eye darkish red, bare, $1.9 \times$ as high as long, gena approximately $1 / 9$ of eye height. Setae and setulae on head black; ocelli darkish yellow, placed close together. Ocellar triangle with short setulae, punctures at bases of setulae conspicuous; frons without setae, orbital setae lacking; postvertical setae erect, considerably stouter and longer than other setulae on vertex. Antenna darkish brown with microtomentum, large, shorter than face; scape and pedicel with black setulae at middle and margin; postpedicel with pubescence, irregularly rectangular, front margin straight, apical margin obtuse, $0.6 \mathrm{~mm}$ long, $0.3 \mathrm{~mm}$ wide, apical angle with stout conical tubercle, nearly as long as surrounding setulae. Proboscis flat and long, brownish yellow, with short sparse black setulae, labellum slightly wide. Palpus short, apically enlarged and rounded, dark brown with short dense black pubescence, margin with short sparse setulae.

Thorax. Shiny, blackish brown with metallic blue-green luster; scutellum shiny, blackish brown. Setae and setulae on thorax black, punctures at bases of setulae deep and numerous; scutellum large, approximately triangular, wide and rounded apically, $0.6 \times$ as long as thorax. Apical setae longer and stouter than other setae. Anepisternum darkish brown with setulae; katepisternum and anepimeron brown, bare. Legs slender, blackish brown except tarsi darkish yellow. Setae and setulae on legs black. Wing hyaline with greenish and purplish reflections, unspotted, slightly $1.5 \times$ as long as wide; veins brown; costal vein (C) extending to end of $\mathrm{R}_{4+5}$ and terminating before apex of wing; subcostal vein (Sc) weak, slightly angulated; $R_{1}$ curved, not angulated, $R_{2+3}$ and $R_{4+5}$ parallel for $4 / 5$ along their lengths, then diverging to wing margin; $\mathrm{r}-\mathrm{m}$ short; $\mathrm{M}_{1}$ between $\mathrm{r}-\mathrm{m}$ and $\mathrm{dm}-\mathrm{m} 1.5 \times$ as long as $\mathrm{dm}-\mathrm{m}, \mathrm{dm}-\mathrm{m}$ slightly sinuous, forming an angle nearly at $90^{\circ}$ with $\mathrm{M}_{4}$, distal portion of $\mathrm{M}_{4}$ ( the part beyond dm-m) $1.5 \times$ as long as dm-m (Fig. 17). Calypter brownish, with brownish microtrichae, margin with brownish setulae. Knob of haltere darkish yellow, stalk brownish.

ABdomen. Brownish black with a metallic blue-green luster, wide and slightly flattened. Setae and setulae on abdomen black. Male terminalia: epandrium (Figs 18-19) slightly wide dorsally, broadest in middle, with setulae; surstylus slightly narrowed and blunt apically; cercus rather narrow, with dense setulae. Hypandrium (Figs 20-21) n-shaped; gonopods small and symmetric; phallus slender, distipallus slightly enlarged.

\section{Female}

Unknown.

\section{Distribution}

China (Yunnan).

\section{Remarks}

This new species is somewhat similar to $C$. sinicum Yang \& Yang, but may be separated from it by $\mathrm{M}_{1}$ between $\mathrm{r}-\mathrm{m}$ and $\mathrm{dm}-\mathrm{m} 1.2 \times$ as long as $\mathrm{dm}-\mathrm{m}$, ocellar triangle approximately in isosceles triangle. In C. sinicum, $\mathrm{M}_{1}$ between $\mathrm{r}-\mathrm{m}$ and $\mathrm{dm}-\mathrm{m} 1.7 \times$ as long as $\mathrm{dm}-\mathrm{m}$, ocellar triangle approximately in equilateral triangle (Yang \& Yang 1996).

\section{Discussion}

The Cryptochetidae is the smallest family in the superfamily Carnoidea. Although the life-habits of cryptochetid flies are rather well known, species are hard to collect. In some places, cryptochetids fly around the human head or eyes. The three new species - C. euthyiproboscise sp. nov., C. glochidiatusum sp. nov. and $C$. longilingum sp. nov. - described in the present paper have some obviously different morphological characters. There are 43 known species of Cryptochetum in the world, ten species are 

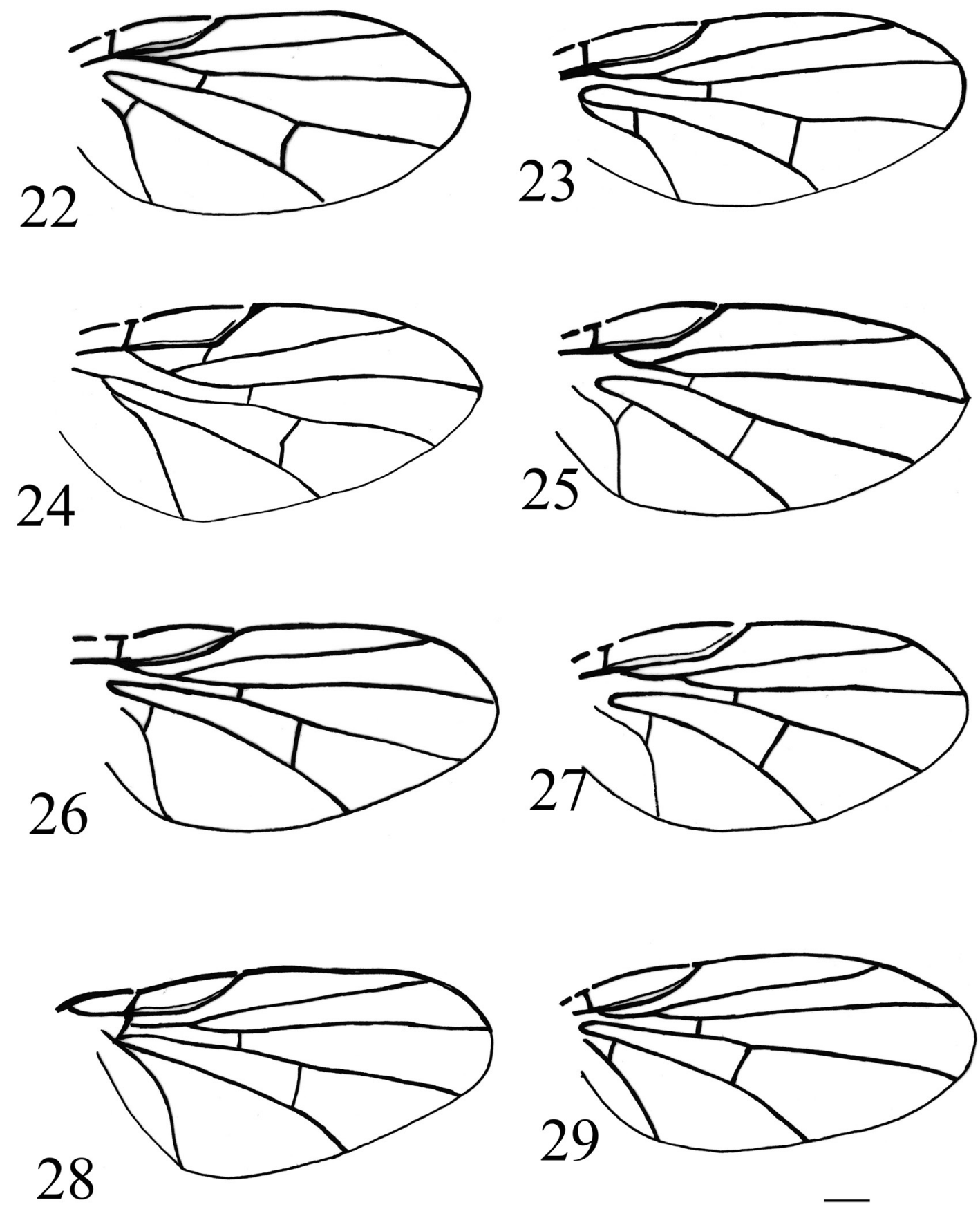

Figs 22-29. Wings of eight species of Cryptochetum. 22. C. curvatum Yang \& Yang, 1996. 23. C. deltatum Yang \& Yang, 1996. 24. C. tianmuense Yang \& Yang, 2001. 25. C. acutulum Yang \& Yang, 1996. 26. C. zalatilabium Xi \& Yang, 2015. 27. C. kunmingense Yang \& Yang, 1996. 28. C. fanjingshanum Yang \& Yang, 1988. 29. C. maolanum Yang \& Yang, 1996. Scale bar $=0.1 \mathrm{~mm}$ 

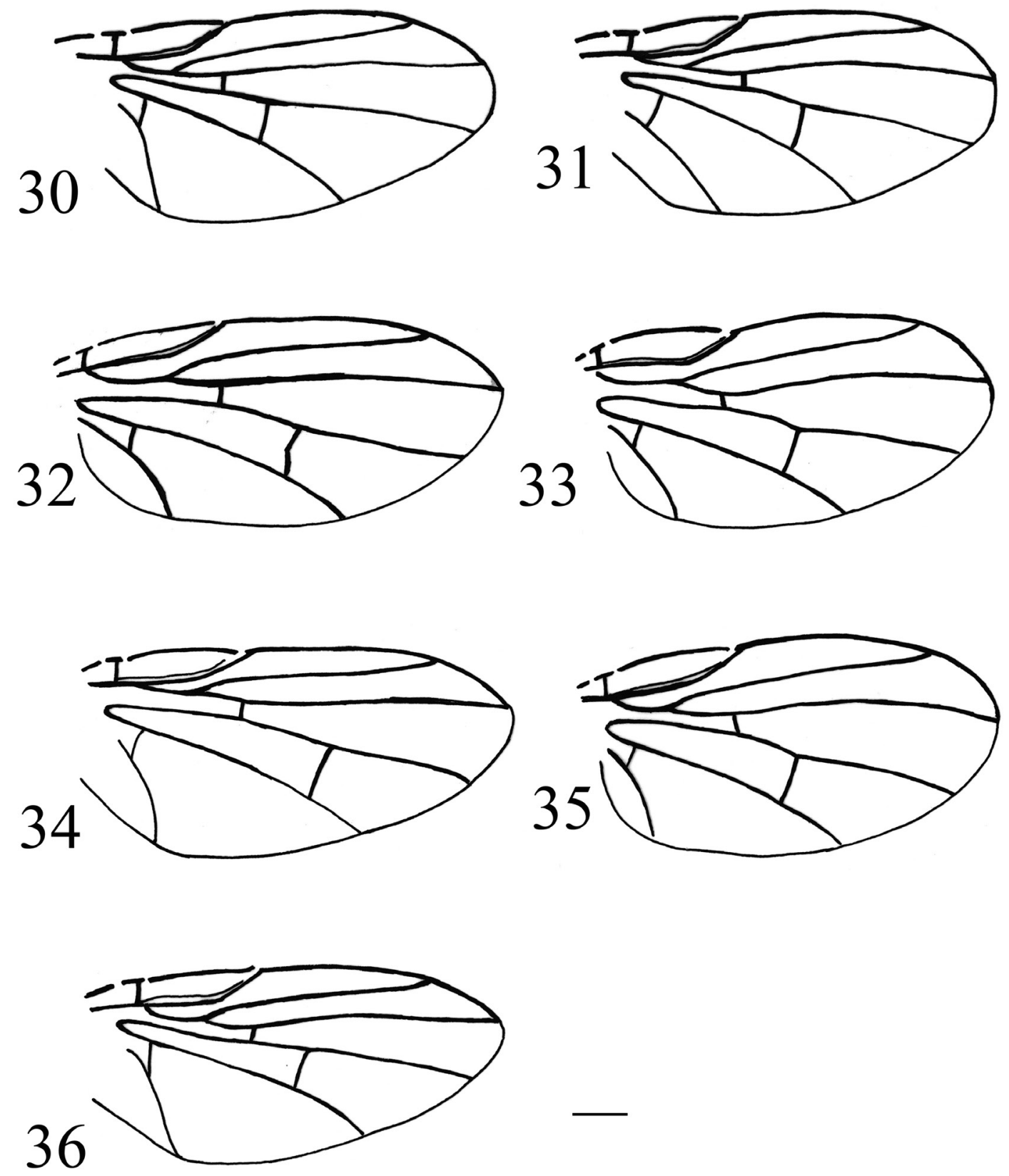

Figs 30-36. Wings of seven species of Cryptochetum. 30. C. shaanxiense Xi \& Yang, 2015. 31. C. yunnanum Xi \& Yang, 2015. 32. C. nonagintaseptem Yang \& Yang, 1998. 33. C. medianum Yang \& Yang, 1998. 34. C. sinicum Yang \& Yang, 1996. 35. C. acuticornutum Yang \& Yang, 1998. 36. C. beijingense Yang \& Yang, 1996. Scale bars $=0.1 \mathrm{~mm}$. 
known in the Palearctic Region (Rondani 1875; Hendel 1933; Cadahia 1984; Nartshuk 1984; Papp et al. 2018) and until now, 15 species were known to occur in China. Five species of Cryptochetidae have been recorded from Yunnan Province (Yang \& Yang 1996; Xi \& Yang 2015). Yunnan is one of the world's well-known regions for extremely rich biodiversity, which reveals the potential cryptochetid speciesrich areas in China. The Chinese fauna of Cryptochetidae is extraordinarily rich, with the continued discovery and description of further species.

\section{Acknowledgements}

The authors express their sincere thanks to Dr Yu-Y. Wang (Baoding), Dr Fei-Y. Liang (Jingzhou) and Dr Wei Zhang (Qingdao), for their kind help and collection of the specimens. This work was supported by the National Natural Science Foundation of China (grant number 31672333), Natural Science Youth Innovation Fund of Henan Agricultural University (grant number KJCX2019A11) and the Agricultural Technology System of Henan (grant number S2014-11-G03).

\section{References}

Cadahia D. 1984. El interés biológico del género Cryptochaetum Rond. Diptera, Cryptochaetidae y descripción de una nueva especie. Boletín del Servicio de plagas forestales 10: 159-184.

Cumming J.M. \& Wood D.M. 2017. Adult morphology and terminology. In: Kirk-Spriggs A.H. \& Sinclair B.J. (eds) Manual of Afrotropical Diptera. Vol. 1. Introductory Chapters and Keys to Diptera Families. Suricata 4: 89-133. South African National Biodiversity Institute, Pretoria.

Foote R.H. \& Arnaud P.H. 1958. Notes on the taxonomy and habit of Cryptochaetum nipponense (Tokunaga) in Japan (Diptera: Cryptochaetidae). Proceedings of the Entomological Society of Washington 60: 241-245.

Hendel F. 1933. Über das Auftreten der in Schildläusen parasitisch lebenden Dipteren-Gattung Cryptochaetum in Deutschland. Zeitschrift für Pflanzenbau und Pflanzenschutz 43: 241-245.

Nartshuk E.P. 1984. Family Cryptochetidae. In: Soós Á. \& Papp L. (eds) Catalogue of Palaearctic Diptera. Clusiidae-Chloropidae. Volume 10: 67-68. Akadémiai Kiadó, Budapest, Hungary.

Papp L., Barták M., Kubík Š. \& Civelek H.S. 2018. Cryptochetidae (Diptera): first record of the family from Turkey. Turkish Journal of Zoology 42: 113-117. https://doi.org/10.3906/zoo-1705-56

Rondani C. 1875. Species italicae ordinis Dipterorum (Muscaria Rndn.) collectae et observatae a prof. Camillo Rondani. Bolletino della Società italiano 7: 166-191.

Thorpe W.H. 1941a. A description of six new species of the genus Cryptochaetum (Diptera-Agromyzidae) from East Africa and East indies; together with a key to the adults and larvae of all known species. Parasitology 33: 131-148.

Thorpe W.H. 1941b. The biology of Cryptochaetum (Diptera) and Eupelmus (Hymenoptera) parasites of Aspidoproctus (Coccidae) in East Africa. Parasitology 33: 149-168.

https://doi.org/10.1017/S0031182000024355

Yang C.K. \&Yang C.Q. 1996. Cryptochetidae. In: Xue W.Q. \& Chao C.M. (eds) Flies of China. Vol. 1: 224-233. Liaoning Science and Technology Press, Shenyang.

Yang C.K. \& Yang C.Q. 1998a. Diptera: Cryptochaetidae. In: Wu H. (ed.) Insects of Longwangshan: 326-327. China Forestry Publishing House, Beijing. 
Yang C.K. \& Yang C.Q. 1998b. The family Cryptochaetidae new to Henan, with two new species (Diptera: Acalyptratae). In: Shen XC \& Shi ZY (eds) Fauna and Taxonomy of Insects in Henan. Vol. 2: 97-99. China Agricultural Science and Technology Press, Beijing.

Yang C.K. \& Yang C.Q. 2001. Diptera: Cryptochaetidae. In: Wu H. \& Pan C.W. (eds) Insects of Tianmushan National Nature Reserve: 502-503. Science Press, Beijing.

Xi Y.Q. \&Yang D. 2015. Three new species of Cryptochetum Rondani from China (Diptera, Cryptochetidae). Transactions of the American Entomological Society 141: 80-89.

https://doi.org/10.3157/061.141.0108

Manuscript received: 18 July 2019

Manuscript accepted: 18 November 2019

Published on: 14 February 2020

Topic editor: Gavin Broad

Desk editor: Eva-Maria Levermann

Printed versions of all papers are also deposited in the libraries of the institutes that are members of the EJT consortium: Muséum national d'histoire naturelle, Paris, France; Meise Botanic Garden, Belgium; Royal Museum for Central Africa, Tervuren, Belgium; Royal Belgian Institute of Natural Sciences, Brussels, Belgium; Natural History Museum of Denmark, Copenhagen, Denmark; Naturalis Biodiversity Center, Leiden, the Netherlands; Museo Nacional de Ciencias Naturales-CSIC, Madrid, Spain; Real Jardín Botánico de Madrid CSIC, Spain; Zoological Research Museum Alexander Koenig, Bonn, Germany; National Museum, Prague, Czech Republic. 